\title{
International Journal of Technology and Engineering Studies
}

volume 7 issue 1 pp. 1-9 doi: https://dx.doi.org/10.20469/ijtes.7.10001-1

\section{Evaluation of a Nanostructured MWCNT based RAM Coating Applied to a Glass Fiber Composite}

\author{
Adil Hassan* \\ National University of Sciences \& \\ Technology, Islamabad, Pakistan
}

\author{
M. Nasir Bashir \\ National University of Sciences \& \\ Technology, Islamabad, Pakistan
}

\author{
Farhan Abbas \\ University of Liege, \\ Liege, Belgium
}

\author{
Ammar Muhammad Khan \\ University of Liege, \\ Liege, Belgium
}

\author{
Ahmed Sohail Ghauri \\ University of Engineering and Technology, \\ Taxila, Pakistan
}

\begin{abstract}
This study presents, shielding effectiveness, complex permeability, and complex permittivity of Multi-Walled Carbon Nanotube (MWCNTs) based Radiation Absorbent Material (RAM) coatings in X-Band (8- $12 \mathrm{GHz}$ ). This study utilized Scanning Electron Microscope (SEM) analysis. RAM coatings were developed using polyurethane dispersion and MWCNTs filler. A series network analyzer tested the prepared coating applied on glass fiber substrate and analyzed it by scanning electron microscope. Results show that shielding effectiveness, relative permittivity, and permeability increase with increased concentration of MWCNT in prepared RAM coating. The sample showed maximum shielding effectiveness with a maximum concentration of MWCNTs. This study presents a comparison between the shielding effectiveness results with different MWCNTs concentrations, which have never been done before, and it carries immense applications in the defense and aerospace sectors.
\end{abstract}

Keywords: MWCNTS, RAM, RCS, nanostructures, GFRP, Polyurethane, matrix material

Received: 11 August 2020; Accepted: 2 January 2021; Published: 27 February 2021

\section{INTRODUCTION}

With the rapid advancements and technological developments in the defense sector, radar absorption has become an important issue with the need to develop modern methods to achieve radar absorption. Stealth technology is a dire need in modern combat tactics. It has become an important issue for defense bodies to enable their assets like missiles, aircraft, and equipment like spy drones to remain undetected from radar. It can be done by reducing Radar Cross-section (RCS) [1, 2].

Radar absorbent material is also known as microwave absorbing material, and radar absorbing materials are abbreviated as RAM [3]. They are classified as materials that minimize the electromagnetic radiation reflectivity and, precisely speaking, especially waves with a frequency in the $\mathrm{X}$ band. RAM can be manufactured in various types and forms. It may be in the form of paints, films, and coated films [4]. They are implied where we want to decrease the RCS, and those structures are correspondingly known as RAS [5]. The military uses them to decrease reflectivity from their asserts to minimize the danger of being detected and attacked. The most prominent application of RAM paint is that when applied on a surface, it changes the impedance properties of the surface, and it acts in a way that hinders the reflectivity of the electromagnetic waves from the surface of the object [6]. The property that allows it to absorb the radiation lies in the absorbing properties related and dependent upon the impedance designing and matching between two variables: air and the object surface itself. We can achieve different impedance values by changing the material used to make the RAM, and the material combination also

\footnotetext{
${ }^{*}$ Correspondence concerning this article should be addressed to Adil Hassan, National University of Sciences \& Technology, Islamabad, Pakistan. E-mail: adilhassan17@yahoo.com

(C) 2021 The Author(s). Published by KKG Publications. This is an Open Access article distributed under a Creative Commons AttributionNonCommercial-NoDerivatives 4.0 .
} 
changes the absorbing capability of the RAM [7].

RAM is classified into two main divisions: narrowband and wideband radar-absorbent material absorbers. The most commonly used absorbent materials are narrowband or resonant. Combining two materials manufactures them, which induced a new material with new properties [8]. The thickness of the RAM coating is proportional to the complex permittivity and permeability, and it can be varied correspondingly to the absorption band we want to overcome [9]. Structural material production is an emerging field, and day by day, many materials are formed by using composites knowledge $[10,11,12]$. These materials have several properties, and many composites are formed to be utilized in the aerospace industry. So, materials with RAM increase certain properties of the material and can be used in many radio wave applications [13, 14]. A polymer composite or a nanocomposite is made up of a polymer infused with filler material, and the filler loading varies depending upon the required characteristics [15]. They have been recently in great attention because of their broad scope of applications. Glass fiber is the future in the aerospace industry, and it is efficient because of its chemical, Mechanical and electrical properties reduce the cost, and it proves a very healthy addition in the aerospace industry, thus replacing lots of conventional materials [8]. RAMS, composed of different materials, has also been prepared, and they all show uniqueness in their properties and the aspect that has innovation is the use of composite glass fibers.

\section{LITERATURE REVIEW}

\section{A. CNTS}

CNTs have lots of favorable properties, and they are excellent conductors of electricity, and they also lead to the production of new materials like plastics. Using CNTs with a matrix material of desirable properties gives us a composite material with unique and required qualities [16]. The primary objectives lie in determining the induced properties developed by preparing a composite material by combining CNTs [17] and polyurethane. Then they are coated on the glass fiber composite, and it was made up of ten layers of glass fibers staked, and they are structured together by using a resin. In the field of advanced nanocomposites, CNTs hold a position because of their superb properties in all respects like physical, mechanical, and electrical [18]. The CNTs are usually infused in a matrix material with affecting their properties. The resulting composite has several desirable properties that cannot be obtained using conventional composites [19, 20, 21]. CNTs were discovered in 1991 by Iijima, and it has been used around the globe in nearly all area of science and composites because of its properties. These properties make it the best reinforcement in composites [22]. The CNT has a cylindrical and curled structure made of graphene. The rolled-out structure of graphene determined the properties of the CNTs, like their morphology, structure, and diameter [23]. CNTs are of two types: single-walled CNTs and multi-walled CNTs. SWCNTs are made up of graphene structure that is single rolled, and its diameter ranges from 1 nanometer to centimeters. Multi-walled CNTs has concentric rolled graphene, and they rolled layer are separated by $0.35 \mathrm{~mm}$ [22].

The chiral angle helps in the determination of the twist in the tube. If the chiral angle is 00 , then the structure is zig zag, and if the chiral angle is 300 , then the structure is armchair. The chirality of CNT greatly affects its mechanical and physical properties [24]. In multiwalled CNTs, weak van der forces are present between the different layers of CNTs with multiple layers. Both types of CNTs have their unique properties. CNTs show all the unique mechanical, magnetic and electrical properties moreover it is lightweight, making them a perfect candidate for space exploration objects [25]. The performance of a CNT-based composite depends on the dispersion made in a matrix and the quality of the infusion of the dispersion [26]. 


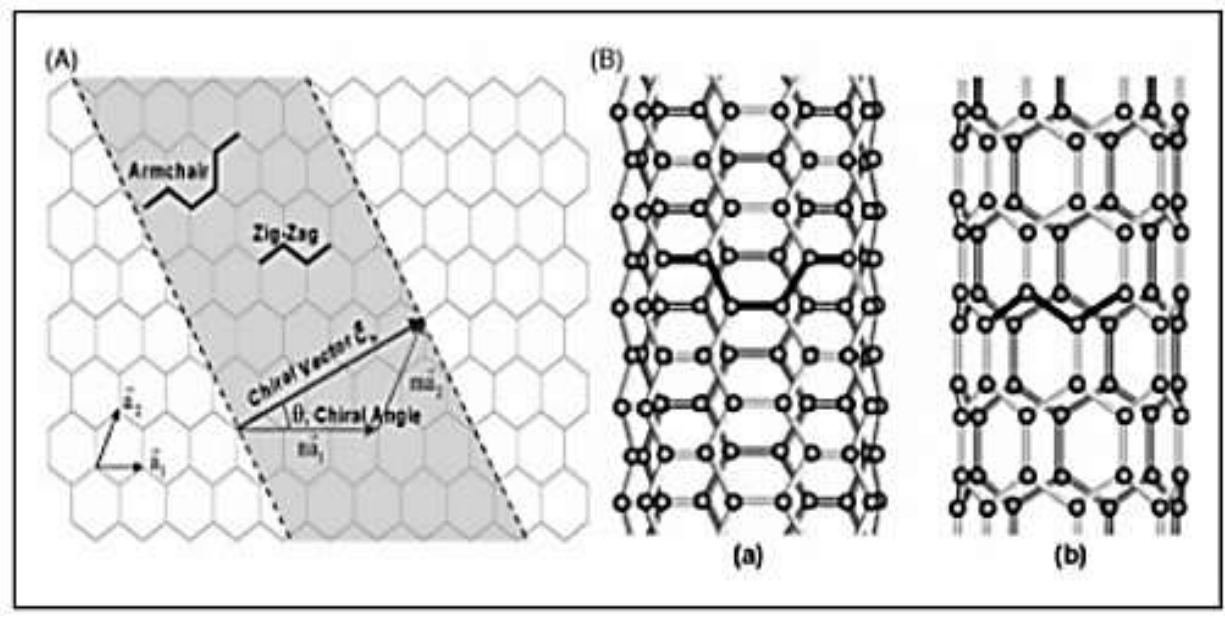

Fig. 1. (A) ACNTs formed from rolled hexagonal graphene; (B) Structure; (a) Armchair (b) Zig zag

\section{B. Matrix Material}

The selection of matrix material depends on numerous variables, including its compatibility with the filler being used. They are chosen for their physical properties, and commonly used matrix materials are polymers like polyurethane, resins, and rubbers. Ceramics are also used [27]. Different types of matrices can be used in the formation of RAM, but the selection of matrix material depends on where we are going to use the matrix and what applications are needed. Polyurethane, PPS, plastic polymers are commonly used in the aviation industry [28], and they are used because of their properties like strength and endurance and resistivity and chemical resistance [29]. Along with CNTs, polyurethane and polyaniline stand better compatible. Polyurethane has a vast range of applications and unique properties. The finished product can be shaped and synthesized according to our needs and requirements [30]. Its properties range from many kinds of matter to rubbery solids, liquids, or soft mixtures. Its main applications are in the field of composites and coatings [31][30]. It has a wide range of properties like flexibility at low temperatures, toughness, and resistance.

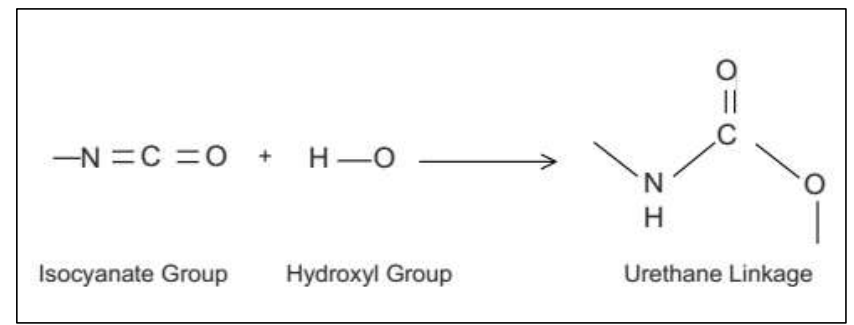

Fig. 2. Urethane linkage structure

The best results are obtained when CNTs are well dispersed [32,33]. We can use different chemicals for dispersion, but polyurethane holds its place because of its properties and excellent results. Typical mixing methods cant be used because of the sensitive processes involved
[34]. For this, a series of processes are done to achieve a dispersion that is best suited for the results [35]. These processes include sonification, dispersion fluid or solvent selection, and a specific temperature for the required desired properties. The most used method is sonification, and it is widely used for nanoparticle dispersion [36]. RAM occupies a vast area of applications stretching from civilian industries to complex military requirements. They serve as an integral element of electronic warfare and are used in 5th generation military aircraft to avoid detection and optimizes the capacity of a military assert to attenuate the returning radar signals from the surface because of deflection. In civilian applications, RAM is employed to reduce electromagnetic interferences and electronic shielding. The aviation industries are shifting towards composites-based structures because of their numerous properties [37]. For that, the innovative side of this research involves two aspects. The composite comprises glass fiber stacked up by ten layers with increased strength and durability, and coatings are made with an indifferent composition of CNTs dispersed in polyurethane matrix at lesser costs and improved efficiencies.

\section{EXPERIMENTAL WORK}

RAMs were prepared using Glass Fiber composites and MWCNTs based nanostructure coatings. The composites which were prepared in the lab using the hand layup technique consisted of 10 glass fiber layers that were cut in proper dimensions, and they are then stacked together and resulted in the formation of a $2 \mathrm{~mm}$ thick GF composite and nanostructured coating applied on this composite was of average $0.25 \mathrm{~mm}$ thickness. The nanostructured coatings used to paint the composites were prepared by mixing MWCNTs with industrialgrade polyurethane $(5 \%, 7 \%, 10 \%$ weight/weight). The 
Polyurethane and MWCNTs were mixed by mechanical agitation for about 6 hours. The coatings were cured at room temperature for about 6 hours. One of the prepared coatings is shown in Fig. 4. The coatings were applied to composites using brushes.

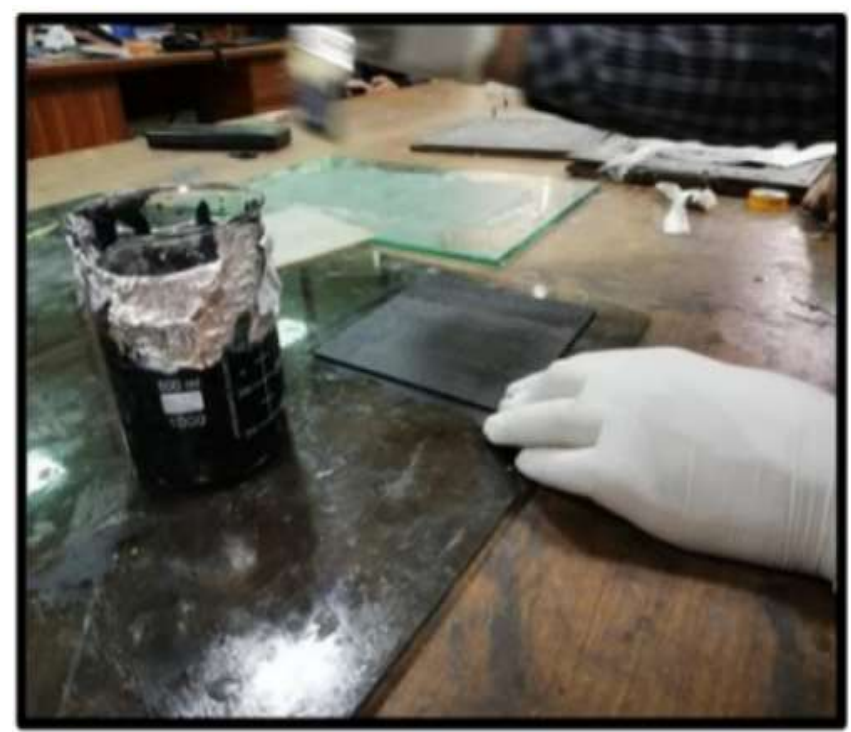

Fig. 3. Preparation of sample S1 (5\% wt/wt)

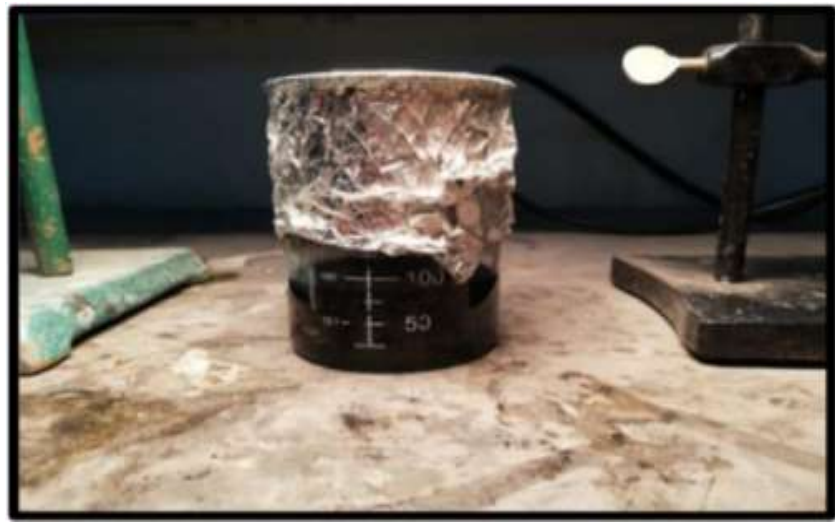

Fig. 4. Prepared RAM coating (5\% wt/wt)

Three samples of specifications as shown in table 1 were prepared and prepared samples are as given above in Fig. 5. Corners of the samples are cut by $1 \mathrm{~cm} \times 1 \mathrm{~cm}$ to prepare samples for SEM analysis.

\section{RESULTS AND DISCUSSION}

Agilent e8362b PNA Series Network Analyzer (shown in Fig. 6 was used to measure and determine the shielding effectiveness of all three samples. A sample of thickness $2 \mathrm{~mm}$ with a coating thickness of $0.25 \mathrm{~mm}$ on each side is placed in the center of two receivers/emitters.

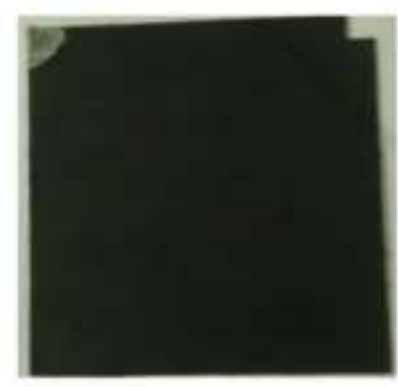

(a) Sample S1

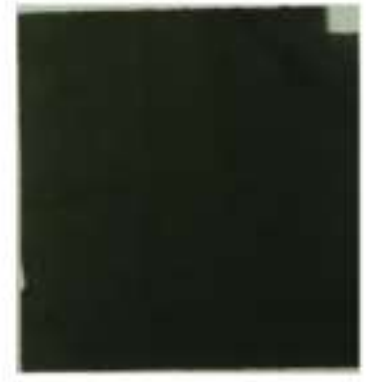

(b) Sample S2

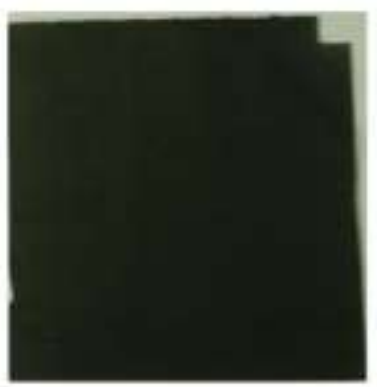

(c) Sample S3

Fig. 5. Prepared samples for testing

\section{A. Shielding Effectiveness}

Comparative analysis of shielding effectiveness of all three samples S1, S2, S3 for Shielding effectiveness is given in Fig. 7. As seen, by increasing the concentration of MWCNTs, the shielding effectiveness of the Sample increases. For example, around $9.5 \mathrm{GHz}$ ( most commonly used frequency by radars), attenuation of EM signal for sample $\mathrm{S} 1$ is $-3.428 \mathrm{~dB}$, for sample $\mathrm{S} 2$, it is $-5.365 \mathrm{~dB}$, and for sample $\mathrm{S} 3$, it is $-19.580 \mathrm{~dB}$. Thus, the RAM coating's percentage absorption and shielding effectiveness increase with increased concentration of
MWCNTs in the coating. Thus, it is clear that MWCNTs can synthesize effective RAM coatings, used in the aeronautical industry. Relative Electric Permittivity and Magnetic Permeability of the samples were obtained, and their real and imaginary values are given shown in the graphs below: A comparison of the relative permittivity of all three samples are shown in Fig. 8. The real part of relative permittivity shows the storage power of the electric part of electromagnetic radiations by the coating. While the relative permittivitys imaginary part shows the dielectric losses by the RAM coating. 


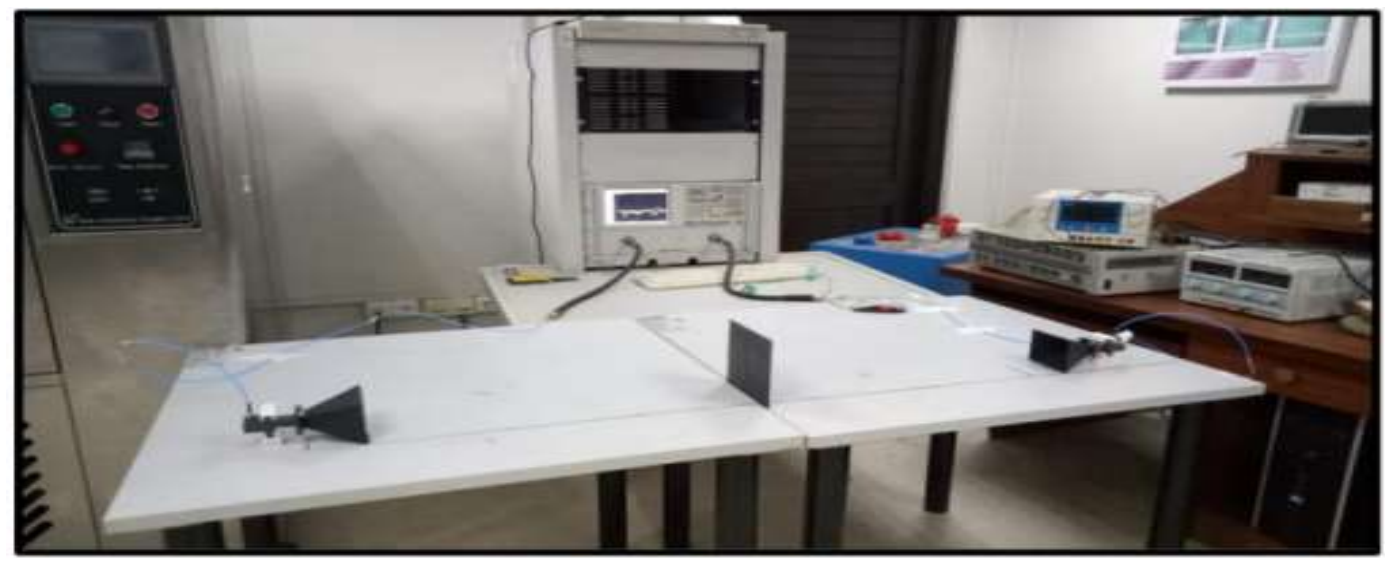

Fig. 6. Measuring shielding effectiveness using agilent e8362b PNA series

An effective RAM coating should have high values of relative permittivity imaginary part. The imaginary part of relative permittivity gives a trend. The coating with maximum wt/wt concentration of MWCNTs gives the highest relative permittivities imaginary part. While the minimum value of relative permittivities, the imaginary part is given by the coating having a minimum wt/wt concentration of MWCNTs.

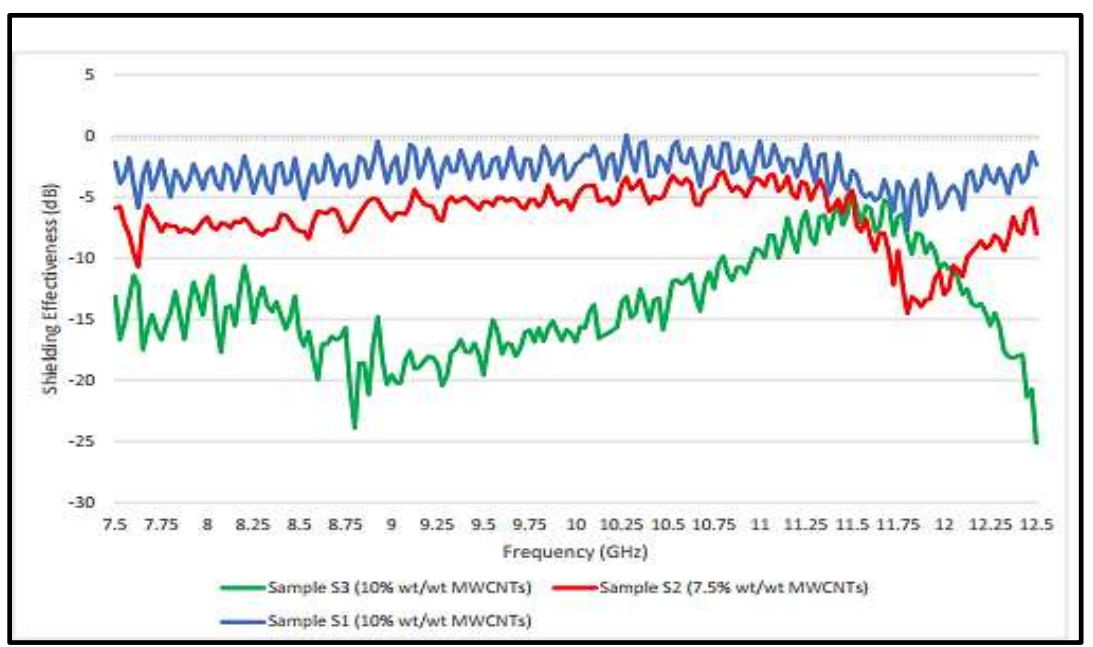

Fig. 7. Shielding effectiveness comparison of samples $\mathrm{S} 1, \mathrm{~S} 2$ and $\mathrm{S} 3$

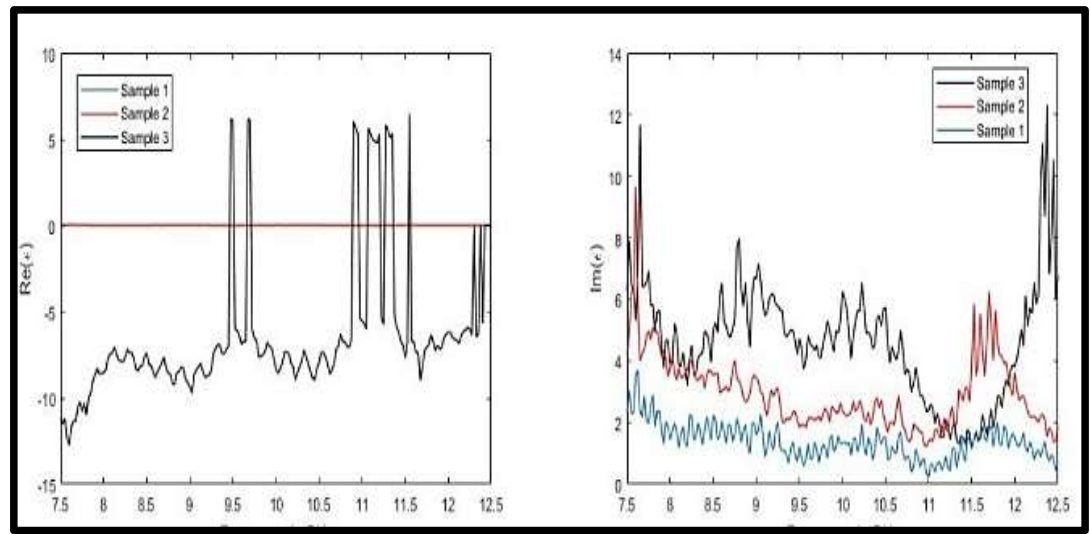

Fig. 8. Relative permitivity of samples S1, S2, and S3 


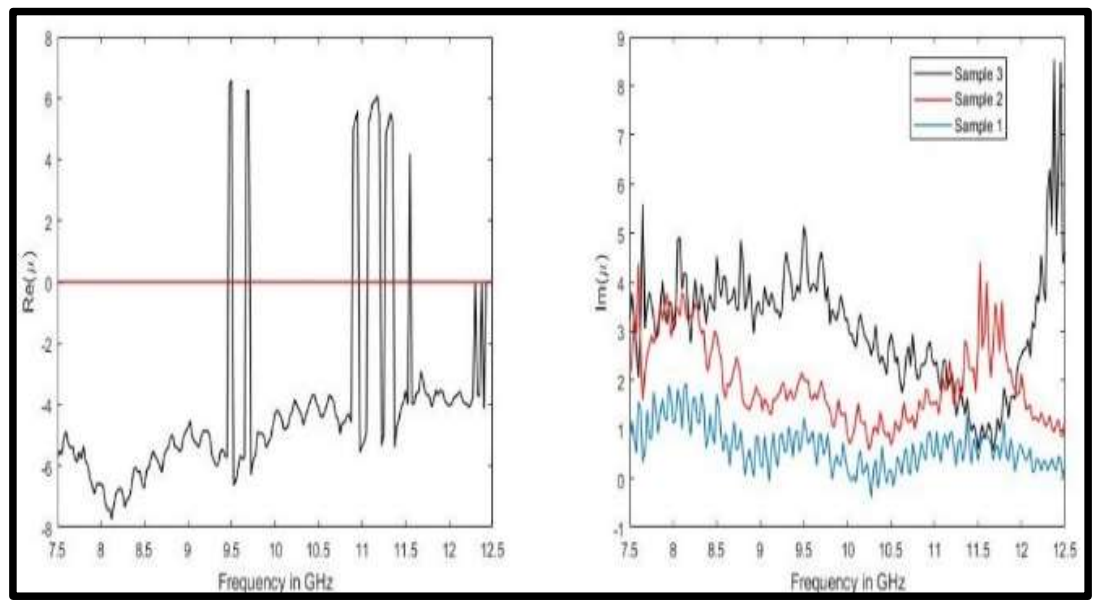

Fig. 9. Relative permeability of sample S1, S2, and S3

\section{B. SEM Analysis}

The morphological characteristics of the samples were examined by using SEM (Tescan vega3). An electron beam is bombarded on the sample surface, and images are obtained, which are then analyzed. It can produce high resolution, three-dimensional images which can provide morphological and compositional information of different materials. SEM analysis was performed on our samples S1, S2, S3 to check the morphological characteristics of the material. The SEM images of the samples and composition indicate that the material has an amorphous structure.

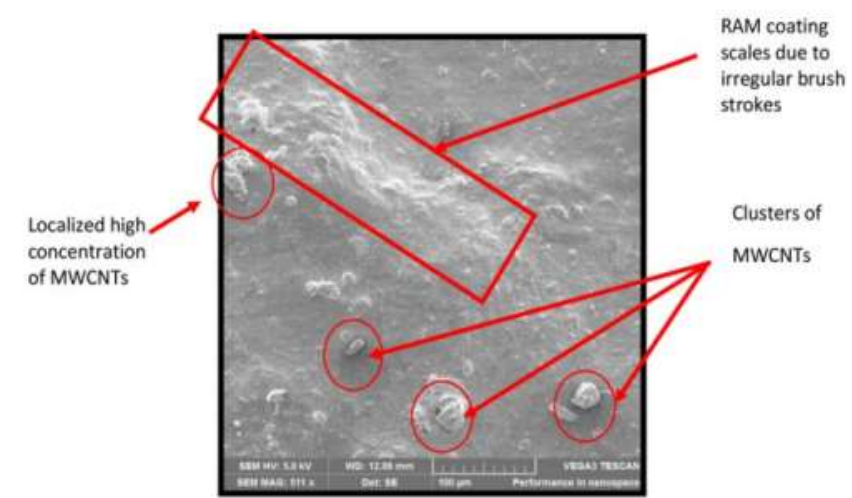

Fig. 10. 511x SEM image of $10 \% \mathrm{wt} / \mathrm{wt}$ MWCNTs concentration prepared

Fig. 10 is a high-resolution image taken by a scanning electron microscope. This image of the coating indicates that the coating has an amorphous structure. In Fig. 10, clumps of MWCNTs can be seen as indicated by red circles. These regions of high concentration of MWCNTS are due to the technique by which radar-absorbent coating was applied on the GFRP substrate. The coating was applied using a paintbrush which is the reason for these clusters. A more uniform coated surface should have been obtained if the vapor deposition method was used instead of the paintbrush technique.

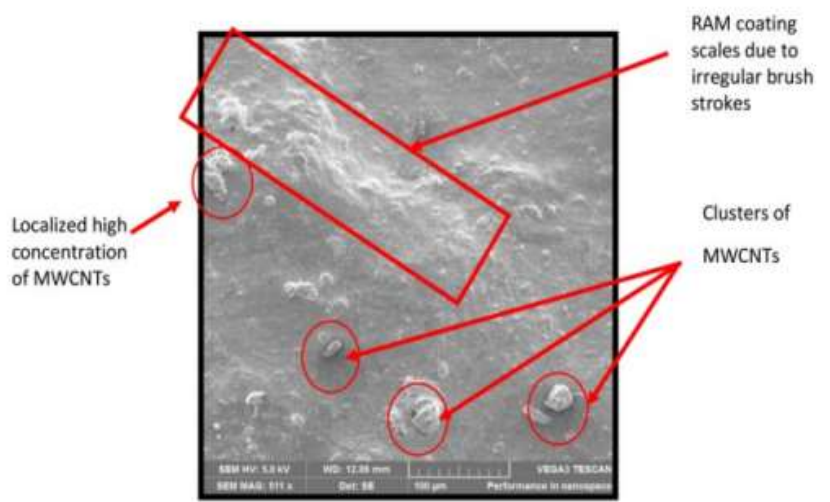

Fig. 11. 508x SEM image of 7.5\% wt/wt MWCNTs concentration prepared

In Fig. 11, a scale-like pattern can be seen. Some clusters of MWCNTs are also indicated in Fig. 11. Region of high the concentration of multi-walled carbon nanotubes is due to the usage of a paintbrush when the coating was applied on the GFRP substrate. While the scale-like pattern in the image is due to the non-uniformity of the direction of paintbrush strokes. Paintbrush strokes should be regular and in a single direction to avoid the scaling of coating on the GFRP substrate. The morphological characteristics of the coating show that the coating has an amorphous structure.

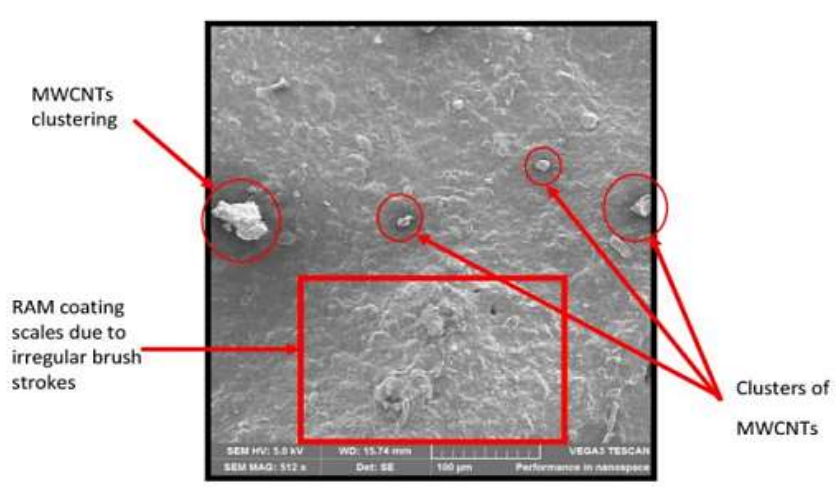

Fig. 12. 512x SEM image of 5\% wt/wt MWCNTs concentration prepared 
As can be seen in Fig. 12, there are clusters. These clusters are due to a high localized concentration of MWCNTs. When the dispersion of MWCNTs and Polyurethane was mixed, the resulting dispersion was homogeneous, i.e., there were no clusters present. However, when the resulting dispersion was coated using a paintbrush, clusters of MWCNTs were formed on the glass fiber substrate. So, to avoid these clusters vapor deposition method should be used instead of using a hand brush for coating purposes. The scale-like structure is also present, which is the result of the irregular direction of paintbrush strokes. These morphological aspects of the coating also show that it has an amorphous structure. As evident and easily seen from figures 10,11 , and 12 , there are clusters, scales-like patterns, and high concentration regions of MWCNTs. When the naked eye sees these coated surfaces, they appear fairly smooth. However, at high magnification, irregularities and defects can be seen. These defects are caused by the technique of applying MWCNTs based coating on the GFRP substrate. The final dispersion was homogeneous, but the paintbrush technique made clusters and scales. These defects can be avoided by using the vapor deposition method for coating RAM on GFRP substrate.

\section{Limitaions of the study}

The limitations of this include the use of expensive materials especially activated multi-walled CNT's. Moreover, the equipment used for the measurement of shielding effectiveness was not easily available. The testing was done against the $8 \mathrm{GHz}$ frequency used by Militaries, and its practical testing against military equipment was difficult.

\section{CONCLUSION AND RECOMMENDATIONS}

In this research work, RAM coatings were prepared experimentally by mechanical agitation of MWCNTs in Thermoplastic Polyurethane coated on Epoxy-based Glass Fiber Reinforced Composite. The Glass Fiber composites were fabricated by employing the hand layup technique. An analysis of the effect of the addition of MWCNTs in RAM coatings has been presented. Shielding Effectiveness measurements of GF composite coated with nanostructure coating of MWCNT have shown that the material can become Radiation Absorbent Material. A coating of $0.25 \mathrm{~mm}$ was applied to the glass fiber substrate. When radiations have impinged on that coating, they penetrate inside and then absorb the incident radiations. The main component responsible for absorption of those radiation was CNTs, thus proving themselves as effective absorbing centers and proving the resulted coating as effective RAM, and proved that CNTs are a good and effective option to be used in RAM and radar-absorbent structures. It is also concluded that with the increase in weight percentage of MWCNTs in the nanostructure coating, the shielding effectiveness of the material changes significantly. For example, around $9.5 \mathrm{GHz}$ (most commonly used radar frequency) attenuation of the EM signal for sample $\mathrm{S} 1$ is $-3.428 \mathrm{~dB}$; for sample $\mathrm{S} 2$, it is $-5.365 \mathrm{~dB}$, and for sample $\mathrm{S} 3$, it is $-19.580 \mathrm{~dB}$. The substrate's glass fiber the provides mechanical strength while nanostructured coating acts as radiation absorbent material, thus giving us a combination with low specific mass and material with a vast range of applications that stretch from military industries to industries.

Further research in this area will include the use of different filler materials as well as different matrix materials for the production of RAM coatings. SWCNTs can be used instead of MWCNT's and their results can be compared to check which one is more effective. Graphene has shown promising characteristics and electrical properties and can be used instead of MWCNT's. Thus, different RAM coatings can be produced by changing the filler materials to check which one is the most efficient and effective for military and aeronautical purposes. Instead of using the Glass Fiber substrate, Carbon Fiber composite or aluminum metal can be used and tested.

Aircraft operate at higher altitudes where temperature and pressure are much higher. That is why we have used TPU because of its resistance to extreme conditions. Further research can be made to check the effect of temperature and drag and lift forces when applied to an aircraft. In this way, the durability of the RAM coatings can be checked and improved. We have tested these coatings in the $\mathrm{X}$ band $(8-12 \mathrm{GHz})$. Further testing can be done in the $\mathrm{Ku}$ band $(12-18 \mathrm{GHz})$ to improve the results further and to check the effectiveness of these coatings in higher bands.

\section{Declaration of Conflicting Interests}

There is no known conflict of interest in this work.

\section{REFERENCES}

[1] K. Vinoy and R. Jha, "Trends in radar absorbing materials technology," Sadhana, vol. 20, no. 5, pp. 815-850, 1995. doi: https://doi.org/10.1007/ BF02744411

[2] L. A. Carlsson, D. F. Adams, and R. B. Pipes, Experimental Characterization of Advanced Composite Materials. Boca Raton, FL: CRC press, 2014.

[3] B. Zohuri, Radar Energy Warfare and the Chal- 
lenges of Stealth Technology. Basingstoke, UK: Springer Nature, 2020.

[4] Y. Ishii, N. Michishita, and H. Morishita, "Optimized design of broadband radar absorbent material," in International Symposium on Antennas and Propagation (ISAP), Busan, Korea, 2018, pp. 1-2.

[5] S. Esmaeli and S. Sedighy, "Wideband radar crosssection reduction by AMC," Electronics Letters, vol. 52, no. 1, pp. 70-71, 2016.

[6] J.-F. Legendre, "New radar absorbent material based of carboned foam glass application to pyramidal radar absorber," Microwave and Optical Technology Letters, vol. 57, no. 1, pp. 18-22, 2015. doi: https://doi.org/10.1002/mop.28769

[7] V. Saxena, "Stealth and counter-stealth some emerging thoughts and continuing debates," Journal of Defence Studies, vol. 6, no. 3, pp. 19-28, 2012.

[8] L. d. C. Folgueras, M. A. Alves, and M. C. Rezende, "Evaluation of a nanostructured microwave absorbent coating applied to a glass fiber/polyphenylene sulfide laminated composite," Materials Research, vol. 17, pp. 197-202, 2014. doi: https: //doi.org/10.1590/S1516-14392014005000009

[9] T. W. Clyne and D. Hull, An introduction to composite materials. Cambridge, UK: Cambridge University Press, 2019.

[10] I. Ali, N. Lin, M. Quazi, M. N. Bashir, H. Sadiq, and F. Sharaf, "Investigating the wear characteristics of metal matrix composite coating deposited on AA5083 Al-alloy by laser surface engineering technique," North American Academic Research, vol. 3, no. 1, pp. 138-146, 2019. doi: https://doi.org/10. 5281/zenodo. 3626448

[11] M. M. Quazi, M. Ishak, A. Arslan, M. A. Fazal, F. Yusof, and a. J. M. Sazzad, B. S., "Mechanical and tribological performance of a hybrid MMC coating deposited on Al17Si piston alloy by laser composite surfacing technique," RSC Advances, vol. 8, no. 13, pp. 6858-6869, 2018.

[12] M. Rizwan, S. Yousuf, M. Sohail, M. N. Bashir, R. Alias, M. Hamdi, and W. Basirun, "Synthesis, characterization, and in vitro biochemical analysis of hydroxyapatitebioglass composite scaffolds for bone tissue repair," The Journal of The Minerals, Metals \& Materials Society, vol. 72, p. 6833692, 07 2020. doi: https://doi.org/10.1007/ s11837-020-04289-z

[13] A. L. Chun, "Carbon nanotubes: Blacker than black," Nature Nanotechnology, 2008.

[14] A. B. Dalton, S. Collins, E. Munoz, J. M. Razal, V. H. Ebron, J. P. Ferraris, J. N. Coleman, B. G.
Kim, and R. H. Baughman, "Super-tough carbonnanotube fibres," Nature, vol. 423, no. 6941, pp. 703-703, 2003. doi: https://doi.org/10.1038/ 423703a

[15] R. A. Vaia and E. P. Giannelis, "Polymer nanocomposites: Status and opportunities," MRS Bulletin, vol. 26, no. 5, pp. 394-401, 2001.

[16] M. J. Oconnell, Carbon Nanotubes: Properties and Applications. Boca Raton, FL: CRC press, 2018.

[17] I. A. Kinloch, J. Suhr, J. Lou, R. J. Young, and P. M. Ajayan, "Composites with carbon nanotubes and graphene: An outlook," Science, vol. 362, no. 6414, pp. 547-553, 2018. doi: https://doi.org/10. 1126/science.aat7439

[18] D. W. Schaefer and R. S. Justice, "How nano are nanocomposites?" Macromolecules, vol. 40, no. 24, pp. 8501-8517, 2007. doi: https://doi.org/10.1021/ ma070356w

[19] P. S. Thomas, A. A. Abdullateef, M. A. Al-Harthi, A. Basfar, S. Bandyopadhyay, M. A. Atieh, and S. De, "Effect of phenol functionalization of carbon nanotubes on properties of natural rubber nanocomposites," Journal of Applied Polymer Science, vol. 124, no. 3, pp. 2370-2376, 2012. doi: https://doi. org/10.1002/app.35274

[20] J. Blackwell and K. H. Gardner, "Structure of the hard segments in polyurethane elastomers," Polymer, vol. 20, no. 1, pp. 13-17, 1979. doi: https: //doi.org/10.1016/0032-3861(79)90035-1

[21] J. Blackwell and M. Ross, "X-ray studies of the structure of polyurethane hard segments," Journal of Polymer Science: Polymer Letters Edition, vol. 17, no. 7, pp. 447-451, 1979. doi: https://doi.org/10. 1002/pol.1979.130170709

[22] J. N. Coleman, U. Khan, W. J. Blau, and Y. K. Gunko, "Small but strong: A review of the mechanical properties of carbon nanotube-polymer composites," Carbon, vol. 44, no. 9, pp. 1624-1652, 2006. doi: https://doi.org/10.1016/j.carbon.2006.02.038

[23] E. T. Thostenson, Z. Ren, and T.-W. Chou, "Advances in the science and technology of carbon nanotubes and their composites: A review," Composites Science and Technology, vol. 61, no. 13, pp. 1899-1912, 2001. doi: https://doi.org/10.1016/ S0266-3538(01)00094-X

[24] M. S. Dresselhaus, G. Dresselhaus, and P. C. Eklund, Science of Fullerenes and Carbon Nanotubes: Their Properties and Applications. Amsterdam, Netherlands: Elsevier, 1996.

[25] J.-C. Zhao, F.-P. Du, X.-P. Zhou, W. Cui, X.-M. Wang, H. Zhu, X.-L. Xie, and Y.-W. 
Mai, "Thermal conductive and electrical properties of polyurethane/hyperbranched poly (ureaurethane)-grafted multi-walled carbon nanotube composites," Composites Part B: Engineering, vol. 42, no. 8, pp. 2111-2116, 2011. doi: https: //doi.org/10.1016/j.compositesb.2011.05.005

[26] Z. Han and A. Fina, “Thermal conductivity of carbon nanotubes and their polymer nanocomposites: A review," Progress in polymer science, vol. 36, no. 7, pp. 914-944, 2011. doi: https://doi.org/10. 1016/j.progpolymsci.2010.11.004

[27] M. Imran and A. A. Khan, "Characterization of Al-7075 metal matrix composites: A review," Journal of Materials Research and Technology, vol. 8, no. 3, pp. 3347-3356, 2019. doi: https://doi.org/10. 1016/j.jmrt.2017.10.012

[28] N. V. Gama, A. Ferreira, and A. Barros-Timmons, "Polyurethane foams: Past, present, and future," $M a$ terials, vol. 11, no. 10, pp. 1841-1842, 2018. doi: https://doi.org/10.3390/ma11101841

[29] A. Gupta, I. Fidan, S. Hasanov, and A. Nasirov, "Processing, mechanical characterization, and micrography of 3D-printed short carbon fiber reinforced polycarbonate polymer matrix composite material," The International Journal of Advanced Manufacturing Technology, vol. 107, no. 7, pp. 3185-3205, 2020. doi: https://doi.org/10.1007/ s00170-020-05195-Z

[30] J. O. Akindoyo, M. D. Beg, S. Ghazali, M. Islam, N. Jeyaratnam, and A. Yuvaraj, "Polyurethane types, synthesis and applications-A review," $R S C$ Advances, vol. 6, no. 115, pp. 114453-114482, 2016.

[31] J. W. Cho, J. W. Kim, Y. C. Jung, and N. S. Goo, "Electroactive shape-memory polyurethane composites incorporating carbon nanotubes," Macromolec- ular Rapid Communications, vol. 26, no. 5, pp. 412-416, 2005. doi: https://doi.org/10.1002/marc. 200400492

[32] A. Jorio, G. Dresselhaus, and M. S. Dresselhaus, Carbon nanotubes: Advanced topics in the synthesis, structure, properties and applications. Berlin, Germany: Springer Science \& Business Media, 2007, vol. 111.

[33] J. Ryszkowska, M. Jurczyk-Kowalska, T. Szymborski, and K. J. Kurzydłowski, "Dispersion of carbon nanotubes in polyurethane matrix," Physica E: Low-Dimensional Systems and Nanostructures, vol. 39, no. 1, pp. 124-127, 2007. doi: https: //doi.org/10.1016/j.physe.2007.02.003

[34] O. Meincke, D. Kaempfer, H. Weickmann, C. Friedrich, M. Vathauer, and H. Warth, "Mechanical properties and electrical conductivity of carbonnanotube filled polyamide- 6 and its blends with acrylonitrile/butadiene/styrene," Polymer, vol. 45, no. 3, pp. 739-748, 2004. doi: https://doi.org/10. 1016/j.polymer.2003.12.013

[35] H. Koerner, W. Liu, M. Alexander, P. Mirau, H. Dowty, and R. A. Vaia, "Deformationmorphology correlations in electrically conductive carbon nanotubethermoplastic polyurethane nanocomposites," Polymer, vol. 46, no. 12, pp. 4405-4420, 2005. doi: https://doi.org/10.1016/j. polymer.2005.02.025

[36] M. J. Schulz, A. D. Kelkar, and M. J. Sundaresan, Nanoengineering of Structural, Functional and Smart Materials. Boca Raton, FL: CRC Press, 2005.

[37] Ö. Yavuz, M. K. Ram, M. Aldissi, P. Poddar, and H. Srikanth, "Polypyrrole composites for shielding applications," Synthetic Metals, vol. 151, no. 3, pp. 211-217, 2005. doi: https://doi.org/10.1016/j. synthmet.2005.05.011 